6. "É essencial para a coisa e para o mundo o que (...) nos permitam algo mais por ver" (Merleau-Ponty 1, p. 146).

7. A referência a um fundo indefinido aparece nas últimas páginas de $O$ Olho $e O$ Espírito (Merleau-Ponty 8).

8. Assim se afirma que ao recordar um momento, A é dado "por transparência através de $A^{\prime}(. .$.$) e assim sucessivamente como vejo o ladrilho através das massas de água que$ deslizam sobre ele" (Merleau-Ponty 10, p. 425).

9. Também um presente de "imbricação", "montagem", "acoplamento" ou "embutimento": gigogne se aplica às mães de muitos filhos, aos móveis e utensílios desdobráveis e às bonecas russas.

10. O texto correspondente aos cursos sobre a natureza é citado em Bimbenet 3, p. 161.

\section{A EXPERIÊNCIA DA FALTA E O MISTÉRIO DO DESEJO}

Silvana de Souza Ramos*

Resumo: O artigo analisa a importância da leitura da obra de Merleau-Ponty no interior da construção da filosofia de Barbaras. Por um lado, trata-se de compreender os limites do corpo próprio para dar conta do a priori correlacional exigido pela fenomenologia. Por outro lado, buscamos desvelar, nos desdobramentos da filosofia da vida proposta pelo filósofo, um horizonte de novos problemas, referidos especialmente à descrição da peculiaridade do desejo humano frente à vida entendida num sentido mais geral. Palavras-chave: Barbaras, Merleau-Ponty, vida, desejo, intencionalidade, mundo.

1. A originalidade de um pensamento pode ser definida por sua capacidade de revigorar certos temas herdados da tradição, conferindolhes um sentido ainda não explorado, uma direção ou um alcance antes invisível. Isso não significa apenas dar um novo significado a determinado conceito ou, ainda, inventar novos conceitos, mas, sobretudo, retomar uma questão - desvinculando-a de certos pressupostos naturalizados ou cristalizados pelo pensamento vigente - de modo a produzir uma resposta inédita. Por um lado, isso exige que o pensador se situe na perspectiva de uma determinada corrente filosófica: o pensador é inicialmente o aprendiz de certa maneira de transitar pelo terreno da idealidade. Por outro lado, não basta incorporar esse estilo: é preciso desdobrá-lo, isto é, assumir a tarefa de pensar por si mesmo. É por isso que uma tradição filosófica só pode enriquecer, ou seja, ampliar nossa potência de pensar, na medida em que se diversifica por meio do trabalho de pensadores individuais.

* Pós-doutoranda pelo Departamento de Filosofia da USP (bolsista Fapesp). 
Não há dúvida de que Renaud Barbaras contempla essas condições: afinal, ele retoma e desdobra um estilo de pensamento, a saber, a fenomenologia. Seu percurso filosófico se inicia com uma leitura cuidadosa de Merleau-Ponty, centrada sobretudo na análise da ontologia indireta proposta pelo filósofo francês. O trabalho de leitor - publicado em seus dois primeiros livros, De l'être du phénomène. Sur l'ontologie de Merleau-Ponty (1991) e Le tournant de l'expérience. Recherches sur la philosophie de Merleau-Ponty (1998) - não pode ser resumido a um simples comentário estrutural, uma vez que teve o mérito de alavancar Merleau-Ponty ao primeiro plano da cena contemporânea, libertando-o da sombra projetada por Sartre. Sob a pena de Barbaras, Merleau-Ponty deixou de ser visto como um mero existencialista coadjuvante ou como um pensador político imerso em suas próprias ambiguidades. Com efeito, a leitura de Barbaras mostrou que a obra de Merleau-Ponty elabora de maneira pertinente as questões centrais da fenomenologia ao reivindicar como condição para o desvelamento do a priori correlacional - isto é, para o entendimento rigoroso da abertura originária do sujeito ao mundo - a consideração intransigente do caráter encarnado e intramundano da subjetividade. Contudo, esse trabalho de interpretação deu ensejo a uma nova perspectiva, já que o caminho percorrido por Barbaras o fez descobrir na empresa merleau-pontiana um verdadeiro limite, o que o levou a dar um passo além, isto é, a produzir seu próprio pensamento. Não devemos, evidentemente, negligenciar o fato de que o filósofo se dedicou ao estudo de diversos pensadores - Husserl, Freud, Lacan, Bergson, Henri, Patocka, Lèvinas, entre outros. Porém, é preciso salientar que a obra de Barbaras até o presente momento - pode ser sintetizada, por um lado, pela tentativa de se desvencilhar dos limites do corpo próprio para adentrar a camada mais profunda do ser intramundano da subjetividade, designado pela transitividade inerente à vida. Em outras palavras, trata-se de radicalizar a perspectiva aberta por Merleau-Ponty - a qual pretende dar conta do a priori correlacional, sem perder de vista o pertencimento do sujeito ao mundo mostrando que tal intuito só pode ser resolvido mediante uma abordagem criteriosa do fenômeno da vida (a um só tempo leben e erleben). Sendo assim, por outro lado, os demais interlocutores de Barbaras aparecem como figuras que desenham no campo teórico diversas abordagens da noção de vida, sem, contudo, dar conta de sua caracterização, quer dizer, sem responder às dificuldades colocadas pela obra de Merleau-Ponty.

2. Isso significa que para compreender a filosofia de Barbaras é preciso inicialmente pôr em relevo a dificuldade imposta pelo ponto de partida do corpo próprio. No prefácio de Vie et intentionnalité. Recherches phénoménologiques (2003), Barbaras oferece uma formulação do eixo central de sua investigação, quando pergunta: "qual é o sentido de ser do sujeito percipiente (quer dizer, da intencionalidade) enquanto ele pertence ao mundo sem, contudo, existir sob o mesmo modo que os outros entes porque é a partir dele que eles aparecem?" (Barbaras 7, p. 12). Essa questão pressupõe uma investigação fenomenológica segundo a qual o centro da pesquisa deve ser ocupado pela relação originária entre sujeito e mundo. Quer dizer, trata-se de evitar a reificação dos termos, o que significa mostrar que a relação os precede: afinal, não há sujeito que não seja aberto ao mundo; inversamente, o mundo só pode aceder à fenomenalidade, isto é, aparecer, para um sujeito. Donde a necessidade de investigar os termos da relação preservando a peculiaridade de cada um deles, o que permite evitar a subordinação de um ao outro, pois o surgimento da visão é ao mesmo tempo a vinda de um ente à visibilidade. Em outras palavras, nenhum dos lados existe antes da relação; assim como nenhuma visada pode suprimir o jorrar das aparições. É preciso, pois, dar conta da relação para que os termos sejam trazidos à luz. Essa é a única via de acesso ao ser do sujeito: pensá-lo como aquele que traz o mundo à visibilidade, sem, contudo, suprimi-lo em sua alteridade em relação ao que aparece. 
Ora, a grande contribuição de Merleau-Ponty para esclarecer esse problema foi ter aprofundado a perspectiva husserliana segundo a qual a percepção só pode ter um acesso inadequado ao mundo, porquanto a doação por perfis obriga o sujeito a uma exploração que nunca se completa. Essa inadequação não se deve a uma limitação de nossas faculdades, pois ela tem um escopo essencial: até mesmo deus apreenderia o mundo inadequadamente através da percepção. Decerto, o objeto se ausenta na medida em que se apresenta, já que um perfil anuncia indefinidamente outro, de modo que o sujeito da percepção jamais pode se apossar do mundo, pois a doação nunca é exaustiva. No plano da fenomenologia de MerleauPonty, a inadequação garante a transcendência do mundo, salvaguardando o caráter originário da correlação sujeito/mundo. Ao mesmo tempo, ela recusa o ideal de objetividade pura preconizado por Husserl e sustentado pela prerrogativa de ausência de limites da razão objetiva.

Sabemos que Merleau-Ponty busca recuperar o mundo da vida mediante a descoberta de um sentido originário do mundo anterior ao saber objetivo. Por isso, desde o prefácio da Phénoménologie de la perception, o filósofo afirma a necessidade de que "a reflexão radical seja consciente de sua dependência em relação a uma vida irrefletida que é sua situação inicial, constante e final" (Merleau-Ponty 13, pp. VIII-IX). Assim, Merleau-Ponty salienta que a redução fenomenológica não deve ser um retorno idealista à consciência constituinte, pois a redução completa configuraria, na verdade, uma reflexão incompleta, já que perderia a facticidade originária do sujeito e do mundo, anterior a qualquer síntese intelectual. Noutras palavras, se a redução fenomenológica nos encaminhasse a um sujeito absoluto que acede às essências, e isso ao preço de nos fazer perder a concretude do mundo indefinidamente aberto à percepção, ela não cumpriria a promessa de nos desvelar o sentido originário da experiência, e só nos forneceria mais uma construção reflexiva do mundo vivido por se alinhar a uma atitude comum a todo intelectualismo.
Por isso, para dar conta do acesso do sujeito encarnado ao mundo, Merleau-Ponty defende que é a intencionalidade operante (fungierende Intentionalität) - e não a intencionalidade de ato - que originariamente anima a experiência concreta (Merleau-Ponty 13, p. VIII). Tal intencionalidade não visa o conhecimento ou a representação de objetos, ao contrário, ela estrutura uma relação de ser no mundo, espécie de conhecimento prático que é um modo original de acesso ao mundo. Com efeito, o debate merleau-pontiano acerca da redução fenomenológica tem um papel fundamental, pois ao recusar a originalidade da intencionalidade de ato, Merleau-Ponty busca recuperar o mundo da vida que o próprio Husserl de Krisis entendia como a camada da experiência negligenciada pelo racionalismo clássico. Segundo Husserl, a racionalidade moderna nasce quando acontece uma mutação no emprego das matemáticas que permite a conquista do infinito, ou, mais precisamente, quando se define a racionalidade como tarefa infinita. O que dá ensejo a essa mutação é a compreensão de que o espaço vivido não comporta a perfeição das formas matemáticas: o espaço vivido é o lugar das gradações ou do inexato. Torna-se necessário, então, submetê-lo a um ideal de perfeição situado no infinito, onde as formas alcançariam a perfeição geométrica. Como observa Barbaras, o objeto científico, concebido sob o paradigma matemático, é "o produto de uma idealização, quer dizer, de uma forma obtida pela passagem ao limite no seio de um processo infinito" (Barbaras 6, p. 66). Sendo assim, o gesto galileano de matematização da natureza nada mais é do que a extensão de um ideal de objetividade à totalidade da natureza. Ora, é esse gesto que funda a racionalidade científica moderna e que consequentemente nos faz esquecer, esclarece Barbaras acerca da posição merleau-pontiana, o sentido aderente ao sensível e, por isso mesmo, anterior à transformação do mundo em objeto de conhecimento. 
Aqui, de fato, Husserl oferece uma formulação interessante, pois o filósofo observa que o movimento galileano de matematização da natureza tem um duplo significado. Por um lado, ele revela como a físicamatemática torna possível transpor para o conhecimento da natureza o método elaborado pela idealidade geométrica. Por outro lado, o método, porque concebido segundo um movimento de idealização da natureza, é uma espécie de subsunção do mundo da experiência, de modo que esta se torna encoberta pela idealidade matemática. Surge então a necessidade de um retorno à experiência velada pelo processo de idealização. Noutras palavras, o reconhecimento de que a ciência é uma idealização da natureza exige que se retorne ao mundo da vida no intuito de esclarecer sua originalidade própria e, consequentemente, sua diferença ou seu excesso em relação à objetividade científica.

É neste ponto, entretanto, que a fenomenologia de Husserl parece insuficientemente radical, aos olhos de Merleau-Ponty. Pois, na verdade, Husserl afirma que o mundo da vida abriga as mesmas estruturas que aquelas da ciência objetiva. Quer dizer, ele é habitado por coisas fechadas sob um conjunto de determinações, o que as torna manipuláveis pelo conhecimento científico. Em suma, isso significa que Husserl não desvela a originalidade do mundo da experiência - isto é, sua aparição pré-objetiva -, pois, no final das contas, há uma continuidade eidética absoluta entre o mundo da vida e o mundo idealizado da ciência. Quer dizer, a diferença entre o exato e o inexato não ameaça em nenhum momento o pressuposto fundamental de que o mundo da vida é um mundo de coisas acessíveis segundo um eidos ${ }^{1}$.

Esse resultado só é possível porque Husserl - mediante a famosa "segunda redução" - reintegra o exterior à imanência, como unidade de sentido, isto é, como objetividade circunscrita por uma consciência absoluta diante do mundo, o que acaba no limite por suprimir a distância inerente à doação do mundo mediante perfis. Merleau-Ponty, ao contrário, pensando a transcendência de um modo não-objetal e não positivo "evita [segundo Barbaras] referir a intencionalidade a algo como uma representação ou uma apreensão de sentido, preservando assim seu movimento centrífugo e por isso mesmo a transcendência do pólo intencional" (Barbaras 7, p. 11). Noutras palavras, o sujeito encarnado visa um etwas, um invisível que não pode se doar sob a forma do objeto, mas que está presente em cada aparição do mundo, sob o modo da ausência. O invisível não é, portanto, um objeto que a consciência sobrevoaria no final do processo de determinação; pelo contrário, ele é inatingível, é transcendência pura, "sem máscara ôntica". Daí que o sujeito permaneça indissoluvelmente ligado a um mundo que lhe escapa reiteradamente, de modo que o movimento que faz o mundo aparecer preserva a diferença do sujeito, isto é, sua distância em relação à exterioridade, a despeito de seu pertencimento ao mundo.

Mas então é preciso perguntar: se Merleau-Ponty acerta na crítica ao primado husserliano do objeto ante a transcendência do mundo, onde está seu limite? A resposta reside no fato de que Merleau-Ponty, ao conceber o sujeito da percepção sob a figura do corpo próprio, acaba por perder o sentido da própria correlação; isto é, acaba por jogar fora o ganho representado pela recusa da originalidade da intencionalidade de ato. Segundo Barbaras, o que faz Merleau-Ponty em Le visible et l'invisible? O filósofo opera uma descrição da experiência do tato, segundo a qual o corpo próprio, ao visar-se, sente-se apreendido como objeto, o que revela que sua carne é também carne do mundo, isto é, que ele tem acesso ao mundo porque compartilha de seu ser. Ora, se o corpo é carne - elemento comum aos entes -, não se pode compreender exatamente como ele pode ser "próprio" - isto é, não-mundo -, e, consequentemente, como ele pode se abrir àquilo que o excede, ou seja, à transcendência. Em suma, se o corpo é no mundo porque é feito de mundo, não se pode explicar como ele se abre 
ao mundo exterior. Noutras palavras, o corpo, na experiência tátil, visase a si mesmo e se descobre mundo. Entretanto, isso, ao invés de marcar sua abertura ao que lhe é exterior, sinaliza seu fechamento numa espécie narcisismo intransponível: o corpo é a um só tempo sujeito e objeto. Por isso, argumenta Barbaras, a reversibilidade carnal, ao mostrar que o tocar tem como contrapartida o ser tocado, retoma a dualidade sujeito/objeto no interior do corpo próprio, mas não garante a correlação sujeito/mundo. Dito de outro modo, o sujeito intramundano é o corpo próprio, mas é feito do mesmo estofo do mundo; não há, portanto, diferença entre os entes mundanos e o sujeito que os faz aparecer. Há, pois, um elemento comum que os permeia, mas isso finalmente não garante a intencionalidade. Daí que a intencionalidade, isto é, o eixo da correlação, se torne inexplicável. É preciso, pois, contra Merleau-Ponty, dar conta da diferença do sujeito em relação ao mundo: e isso só se realiza, segundo Barbaras, substituindo o corpo próprio pela vida. É a vida que dá conta da relação simultânea de pertencimento e de inadequação entre sujeito e mundo, reiterada pela intencionalidade. Mas não se trata da vida tal como é pensada pela tradição, e sim da vida compreendida como desejo, ou seja, como abertura originária à transcendência, "verdade da intencionalidade" (Barbaras 7, p. 23).

Chegamos, assim, à seguinte situação: por um lado, é preciso agarrar o ganho teórico de Merleau-Ponty, qual seja, a exigência da intramundaneidade do sujeito, a garantia de que ele não sobrevoa nem domina os entes mundanos porque não pode recolher o mundo no interior de si. Por outro lado, é preciso que o enraizamento do sujeito não signifique sua identidade com o mundo, pois o sujeito não é um ente entre os entes, uma vez que seu modo de ser difere dos outros entes: o sujeito é aquele que traz o mundo à visibilidade; ele não é simplesmente um visível entre os visíveis.
3. Isso significa que o pensamento de Merleau-Ponty, a despeito da precisão com que levanta inicialmente o problema do a priori da correlação, exige a entrada em cena de outros autores, capazes de propiciar uma abordagem conceitual da vida - a um só tempo viver, no sentido de estar vivo (leben, intransitivo), e viver, no sentido de experimentar algo (erleben, transitivo) - passível de dar conta daquilo que de certo modo antecede a própria existência encarnada, entendida como corpo próprio. Nesse desafio de investigar o caráter originário da vida - enquanto sujeito da correlação -, Barbaras encontra sempre, nalguma medida, os seguintes problemas interligados:

a) a redução da vida ao funcionamento do vivente.

O que significa que a vida é sempre pensada como propriedade do vivente e não como aquilo que dá ensejo ao vivente. Noutras palavras, parte-se do princípio de que o vivente é uma existência já realizada, capaz por isso de viver, e não uma produtividade que se confunde com o viver; isto é, que se produz ao viver.

b) a determinação do funcionamento do vivente como autoconservação ou sobrevivência.

Quer dizer, sendo o vivente uma existência realizada, sua vida só pode ser ou a apropriação do exterior no sentido de preservar seu próprio ser, ou a resistência à ameaça vinda do exterior, a qual pode destituí-lo de seu ser.

c) a assimilação da pulsão - que seria a verdade do instinto animal - à necessidade ou carência circunscrita.

Esse aspecto é fundamental, porque mostra a ausência de erleben no leben: o que define o animal é a pulsão, isto é, a necessidade de algo determinado e não a abertura à indeterminação do mundo. Noutras palavras, a pulsão visa algo de que o animal carece, por isso a abertura do vivente é na verdade a antecipação daquilo que ele busca no exterior. Não haveria, portanto, uma relação desinteressada do animal com o mundo. Em suma, 
o animal não contempla verdadeiramente o mundo, já que só encontra nele aquilo que lhe interessa. O que nos leva ao último ponto.

d) a concepção tradicional da vida engendra um corte radical entre vida e percepção, e é isso que no limite impede de tomar a vida - o devir encarnado do vivente - como a forma primordial da subjetividade, isto é, seu modo de ser originário. Pois, se a vida é essencialmente intransitiva, ela não pode ser o segundo termo da relação com o mundo; ela não pode ser, portanto, o sujeito da percepção.

A abordagem de Heidegger é exemplar nesse sentido, como mostra a análise feita por Barbaras em Vie et intentionnalité. No curso intitulado Die Grundbegriffe der Metaphysik, o filósofo alemão aborda a animalidade através da ideia de pulsão. O intuito é mostrar que o animal - cujo comportamento é circunscrito pela pulsão - não pode ter acesso ao ente enquanto tal. É claro que, diferentemente da pedra, que é sem mundo, o animal tem de algum modo acesso à exterioridade, mas esse acesso é pobre de mundo. Isso porque a pulsão não comporta virtualidade, pois ela projeta antecipadamente o que pode realizar. Consequentemente, na pulsão, o animal não escapa verdadeiramente de si mesmo: pelo contrário, ele é tomado por si mesmo, quer dizer, está sob a égide de si mesmo porque só pode buscar no mundo aquilo de que carece (Barbaras 7, pp. 186 e ss.).

Sendo assim, para o vivente, a exterioridade não aparece enquanto tal, ao mesmo tempo em que ele não se transforma na e pela relação, porque não há verdadeira correlação entre vivente e meio. Heidegger explica o modo de ser da pulsão pelo conceito biológico de desinibição, o qual implica uma relação restrita com o excitante. Nas palavras de Barbaras:

o excitante só existe a serviço do que ele desinibe, é apenas seu próprio poder desencadeante e eis porque ele não pode dar-se, pois só aparece, por assim dizer, desaparecendo. Tal é o sentido verdadeiro da tese da pobreza em mundo: o animal está aberto ao que desinibe e não pode, portanto, ter mundo, pois desta abertura é «precisamente retirada a possibilidade de ver o que desinibe se manifestar enquanto tal» (Barbaras 7, p. 188).

4. Eis que se desenha o desafio de Barbaras frente à tradição: é necessário renunciar à ideia de pulsão (e a compreensão do instinto aí implicada), o que significa desvincular a vida de seu narcisismo intransponível, isto é, de sua incapacidade de contemplar o mundo de maneira desinteressada. Trata-se de chegar ao vivente partindo da vida e não o inverso, mostrando que ele não é uma existência determinada ou acabada, mas um processo de individuação que se confunde com a experiência transitiva do viver, como indicara Simondon em outro contexto ${ }^{2}$. Isso permitiria qualificar o dinamismo vital como autorrealização e não como autoconservação, o que implicaria, finalmente, caracterizar a pulsão como desejo, isto é, como abertura indeterminada à transcendência. Eis os três momentos constitutivos de uma nova abordagem da vida através dos quais Barbaras realiza o salto teórico fundamental que permite mostrar que no desejo, pulsão e percepção se encontram, ou, melhor, que nele essa dicotomia é superada. Assim, a vida pode finalmente ocupar o lugar do sujeito da correlação.

Mas esse percurso sugere um esclarecimento acerca do modo de ser do desejo, isto é, exige afastá-lo de qualquer identificação com a carência ou a necessidade. O desejo é o devir da vida na medida em que se reporta à exterioridade. Ele não é necessidade de alguma coisa que se poderia nomear ou enquadrar na forma do objeto. Assim, enquanto a necessidade ou a carência supõe a plenitude de um sujeito que precisa se preservar, o desejo supõe um sujeito que está constantemente em questão, porque o seu movimento em direção ao mundo é sua própria realização. Contudo, essa realização é sempre frustrada, porque o desejo não visa nada, ele tende 
à totalidade e essa não pode ser determinada, isto é, não pode aparecer. Assim, em cada visada, o desejo se determina momentaneamente, para remeter-se além do que atualmente visa. Parafraseando uma formulação de G. Lebrun em seu comentário sobre a razão kantiana, o desejo visa um além que não se resolve na forma do ali, isto é, ele deseja desfazer uma distância que se reitera em cada momento de presença ou de proximidade. Em suma, o desejo é desejo de nada, de nada objetivo; ele não está atado a nenhum objeto, no sentido de que nada pode preenchê-lo, e, por isso mesmo, ele é suscetível de tudo acolher. Pois, relacionando-se com o que está além de todo objeto finito, ele abre uma transcendência pura, que não é a transcendência de um transcendente - ou de objetos determinados -, e no seio da qual a aparição pode finalmente ter lugar.

Mas isso não resume o que se pode falar acerca do desejo. Com efeito, sua insatisfação intrínseca e seu devir inelutável remetem a uma experiência originária do si constituída na distância. Uma vez que no desejo o sujeito se torna o que ele é, há que se admitir que o desejo é desejo de si por intermédio do transbordamento na exterioridade. Nas palavras de Barbaras: "no desejo o outro é identicamente o que manifesta o si e o que o nega: a insatisfação do desejo, enquanto desejo de si, corresponde precisamente ao fato de que o outro só apresenta o si como sempre ausente" (Barbaras 3, p. 304). O que equivale dizer que o outro é sempre a experiência da perda - ou da "falta" - de si.

A exploração da dinâmica do desejo revela, portanto, sua insatisfação constitutiva, a qual dá sentido à motricidade inerente ao viver, pois o encontro com a alteridade é distância de si e do mundo (de tal modo que a proximidade e a distância originárias são a condição da experiência do tempo e do espaço objetivos). A presença do mundo é sempre ausência do que é visado pelo desejo; simultaneamente, essa distância do mundo faz surgir um sujeito sempre faltante, falhado, cujo preenchimento seria sua própria extinção. O mistério do desejo reside em que aquilo que lhe "falta" ou, mais precisamente, o que o constitui como "falta" - o que o coloca em contato com a distância inexorável do mundo - é exatamente a ambição por aquilo que poderia dissolvê-lo (porque o destituiria de sua falta constitutiva, fazendo-o dissolver-se no mundo). Sendo assim, enquanto viver, o desejo só pode ser apreendido como falta porque só encontra na exterioridade a ausência daquilo que busca, sob o risco de esfacelar-se.

É por isso que Barbaras se refere, muito rapidamente é verdade, à figura do melancólico como expressão do desejo primordial, uma vez que a verdadeira busca é a busca sempre frustrada de si mesmo na alteridade (o desejo é a ambição de abraçar a plenitude); busca que se realiza sob a forma da pulsão de morte, isto é, como tentativa frustrada de reunir-se com a exterioridade. Por isso, a morte não é uma possível destruição que ameaça a vida do exterior (como pensavam os teóricos da vida circunscrita sob uma essência determinada), mas aquilo sobre o que o desejo tem de triunfar, intensificando a inadequação inerente à vida. Afinal, a busca da proximidade absoluta só poderia se realizar plenamente através da morte. A morte está, como diz Barbaras, atrás da própria vida.

5. A abordagem de Barbaras fornece diversos ganhos teóricos, embora coloque problemas os quais eu gostaria de destacar e de discutir através de um novo embate com Merleau-Ponty. Por um lado, estamos diante de uma profunda reflexão sobre o tema da vida, capaz de dissolver as perspectivas tradicionais que nos impedem de vencer os limites das filosofias centradas na figura do sujeito de sobrevoo - sendo assim, Barbaras retoma e revigora o projeto merleau-pontiano de produzir uma fenomenologia não-idealista. Afinal, pensar o sujeito como desejo significa verdadeiramente compreendê-lo em seu devir e em sua abertura ao transbordamento do mundo, pois a vida se produz no interior da experiência e não pode ser absorvida por um princípio de razão suficiente. 
Por outro lado, a identificação entre vida e desejo - uma vez que desfaz a cisão entre viver e perceber - abre a possibilidade de recusar a distinção estanque entre instinto e libido: a vida é desejo, quer dizer, ela não pode ser considerada como uma coisa incapaz de experiência, exatamente porque ela é intrinsecamente experiência ${ }^{3}$. Contudo, esse percurso me leva a algumas questões, as quais na verdade expressam ausências ou limites dessa retomada do problema da correlação e da questão do sujeito enquanto desejo. Falo de ausência no sentido que Barbaras a entende: como aquilo que é exigido pela presença, isto é, aquilo que me causa ansiedade porque considero que já está lá virtualmente, ainda que não seja tematizado diretamente.

Os desenvolvimentos do pensamento de Barbaras ainda não resolvem um problema crucial: como pensar os diferentes modos de vida, isto é, como dar conta de seus níveis de complexidade? Não tocando nessa dificuldade, Barbaras deixa em aberto outra pergunta: como diferenciar uma vida que produz espécies de uma vida que produz cultura, isto é, como dar conta da vida humana propriamente dita? Vejamos como tais dificuldades se configuram.

Em primeiro lugar, causa estranheza o primado da melancolia no interior de uma filosofia da vida, pois ele mostra que estamos diante de um viver ainda solitário. Decerto, esse primado revela que há um investimento originário em si mesmo, pois a busca pela proximidade absoluta é uma busca por si mesmo. É claro que Barbaras fala várias vezes sobre o erotismo e o amor (anunciando inclusive que dedicará um livro a esse tema), mas em nenhum momento outra vida aparece verdadeiramente em sua obra, já que nunca a intersubjetividade é abordada diretamente. Devemos considerar que estamos diante de um pensamento em construção, o que poderia explicar por que esse tema ainda não foi tratado. De qualquer modo, tomo aqui a liberdade de refletir a partir do que está dado ${ }^{4}$. Sabemos que uma das lições de Merleau-Ponty é ter mostrado que a intersubjetividade é inerente ao sujeito: o sujeito não é apenas abertura ao mundo que o ultrapassa; ele é presença/ausência do e para o outro. Isso não é de modo algum derivado em Merleau-Ponty. Afinal, como sair do solipsismo ou do narcisismo sem passar pelo outro, isto é, sem se defrontar com o olhar alheio? Ora, para responder a essa dificuldade, no caso de Merleau-Ponty, não basta abrir o sujeito para o mundo já que a formação dos sujeitos e a experiência de qualquer objetividade - ou da exterioridade num sentido mais amplo exigem a aparição de outros que compartilhem um mundo comum ${ }^{5}$.

Em segundo lugar, é significativo que Barbaras em nenhum momento trate do passado, a não ser como morte. O passado seria a proximidade absoluta em relação à qual o desejo tem o sentimento de nostalgia. Quer dizer, o passado é a completude de certo modo perdida e, no limite, ansiada pelo desejo sob a forma da pulsão de morte. Evidentemente, essa formulação dificilmente poderia se adequar ao pensamento de MerleauPonty ${ }^{6}$. Na Phénoménologie de la perception, o passado são os poderes corporais reificados na forma de hábitos, ou seja, de resíduo empírico (lembremos que o hábito é a queda no empírico daquilo que um dia foi criação). Sendo assim, o sujeito encarnado oscila entre a criação de novos comportamentos e a disposição de montagens adquiridas e sedimentadas em sua existência anônima ou corporal. Noutras palavras, o sujeito dispõe de certos comportamentos adquiridos - ou instituídos ao longo de sua vida - os quais são constantemente retomados em sua existência pessoal. Por isso, Merleau-Ponty afirma que o presente da experiência é denso, pois conta com o passado e se abre a um futuro onde o possível pode desabrochar através da aquisição ou criação de comportamentos inéditos.

Mas isso não é tudo o que encontramos em sua obra. MerleauPonty tem uma belíssima abordagem do passado em seus últimos escritos, mas ela depende inteiramente de uma nova apreensão do passado e da 
originalidade da intersubjetividade, pois se trata de dissecar como se constrói um imaginário ou uma espécie de história dos investimentos que vão tramando a vida afetiva do sujeito. Isso significa que a experiência acaba por carregar certas imagens de conteúdo afetivo; esse conteúdo é revigorado quando uma nova experiência se realiza, de modo que as aparições do mundo e dos outros ganham sempre uma nova espessura. Noutras palavras, é o passado que dá densidade à experiência, a tal ponto que o inconsciente se torna totalmente exteriorizado em Merleau-Ponty, uma vez que ele se cristaliza na exterioridade do mundo e contamina a relação entre o sujeito e aquilo que é trazido à visibilidade. Com efeito, o inconsciente é a carga afetiva visada na aparição externa, propiciada por seu modo diacrítico de doar-se. Isso nos leva a uma diferenciação importante. Nas primeiras obras de Merleau-Ponty, o inconsciente e o passado são de certo modo "interiorizados" no corpo próprio, na forma de hábitos, isto é, sob a forma de resto empírico depositado no esquema corporal (aspecto bastante criticado por Barbaras, uma vez que evidencia uma abordagem naturalista do corpo, presente na Phénoménologie de la perception). Porém, este não é o caso do último Merleau-Ponty, porque então se trata de engendrar uma compreensão expressiva do passado, mostrando que ele ronda a experiência como uma espécie de usina produtora de símbolos ou de matrizes simbólicas partilháveis ${ }^{7}$.

Isso nos permite retomar o problema da correlação discutido por Barbaras, agora nos termos do último Merleau-Ponty. Uma vez que o passado dá profundidade à experiência presente, ele acaba por intensificar a distância dos entes e dos outros. Há em cada imagem do mundo mais do que ela apresenta atualmente porque cada coisa remete a eventos passados com os quais carrega algum tipo de ligação ${ }^{8}$. Dito de outro modo, perante a vida, um ente não é só a sua presença transbordante em direção a um mundo presuntivamente visado, mas também tudo aquilo a que ele remete no interior da experiência acumulada - só assim ele pode ser um pivô capaz de abrir diferentes dimensões de experiência. É por isso que MerleauPonty aborda em seus últimos escritos a transitividade entre presente, passado e futuro, trazendo para a compreensão da temporalidade o modelo diacrítico, o que permite dar um novo sentido para a ideia de retenção. Por essa via, Merleau-Ponty abre um campo de pesquisa no interior do qual a exploração do funcionamento da memória pode alavancar elementos para que possamos dar acabamento a uma filosofia da vida, pois permitiria dar conta da complexidade das diferentes formas de vida. Noutras palavras, o devir inerente à vida singular opera segundo seu poder de abertura ao mundo: isso pode ser notado em toda e qualquer vivente. No entanto, é preciso considerar que a vida humana produz um fundo de memória o qual dá densidade às suas visadas segundo um nível de complexidade que não pode ser encontrado na vida biológica.

Em Barbaras, entretanto, não há ainda uma estratégia que permita pensar, num sentido mais concreto, a experiência da retenção, isto é, o acúmulo de experiência a partir do qual se delineiam a história individual e coletiva. Devemos salientar que o filósofo não aceita o conceito tradicional de retenção uma vez que ele remete ao primado da consciência - isto é, à ideia husserliana de vivido. Ora, é preciso dizer, contudo, que MerleauPonty dispensa o modelo idealista da retenção porque consegue transpor o passado para a exterioridade, valendo-se inclusive de uma inovadora teoria do imaginário. Segundo o filósofo, o passado é aquilo que viso na profundidade dos entes, e isso não nos conduz apenas ao desvelamento de um desejo primordial de completude - testemunhado pela inelutável distância do mundo -, mas a uma abertura que não cessa de expandir-se, por conta da estrutura diacrítica - e simbólica - que rege a aparição dos entes. Não fornecendo ainda um substituto para a ideia de retenção, Barbaras assinala apenas que o passado é uma ausência que não pode apresentar-se 
(daí que ele se resolva na forma da nostalgia). Sendo assim, o anterior - no sentido do originário - é uma fratura, uma falta constitutiva do sujeito, que se repõe a cada nova visada do mundo. Porém, essa cisão originário, embora esclareça o a priori correlacional sem suprimir quaisquer dos termos - o que é um ganho teórico indiscutível -, não pode explicar ainda o que vem depois, isto é, o que se retém ao longo da reiterada experiência da falta, dando ensejo à cultura em seus diversos níveis propriamente humanos.

\section{THE EXPERIENCE OF THE LACK AND THE MYSTERY OF THE DESIRE}

Abstract: This paper analyzes the importance of the reading of the Merleau-Ponty's work within the construction of the Barbaras's philosophy. On the one hand, it is to understand the limits of the body itself in order to account for the a priori required by the phenomenology. On the other hand, we seek to uncover, in the unfolding of the philosophy of the life proposed by the philosopher, a horizon of new problems, especially referred to the description of the peculiarity of human desire towards life understood in a broader sense.

Keywords: Barbaras, Merleau-Ponty, life, desire, world, intentionality.

\section{REFERÊNCIAS BIBLIOGRÁFICAS}

1. Barbaras, R. De l'être du phénomène. Sur l'ontologie de Merleau-Ponty. Paris, Millon, 2001.

2. __ Introduction à la philosophie de Husserl. Paris, Les Éditions de la transparence, 2008

3.__. Introduction à une phénoménologie de la vie. Paris, Vrin, 2008.

4._L_ Le désir et la distance. Introduction à une phénoménologie de la perception. Paris, Vrin, 1999

5. __ Le mouvement de l'existence. Études sur la phénoménologie de Jan Patocka. Paris, Transparence, 2007.

6. Le tournant de l'expérience. Recherches sur la philosophie de MerleauPonty. Paris, Vrin, 1998.

7. . Vie et intentionnalité. Recherches phénoménologiques. Paris, Vrin, 2003.
8. Merleau-Ponty, M. La prose du monde, Paris, Gallimard, 2004.

9. . La Nature. Cours du Collège de France. Paris, Seuil, 1994

10. _. L_institution la passivité. Notes de cours au Collège de France - 19541955. Paris, Belin, 2003

11. . Le structure du comportement. Paris, PUF/Quadrige, 2001.

12. L__. Le visible et l'invisible, Paris, Gallimard, 2004.

13._._. Phénoménologie de la perception. Paris, Gallimard, 1945.

\section{NOTAS}

1. A respeito, cf. especialmente o cap. III da parte I de Le tournant de l'expérience. 2. Cf. G. Simondon. L'individuation psychique et collective. À la lumière des notion de Forme, Information, Potentiel et Métastabilité, Paris, Aubier, 2007.

3. É claro que a noção de experiência ganha aqui um sentido novo, já que ela se desvincula da idéia de vivido: o vivente, seja qual for, deve ser compreendido como um movimento de existência. Barbaras retira essa formulação da fenomenolgia de Patocka (cf. Barbaras 5, pp. 7-28).

4. As análises feitas neste artigo só consideram o que Barbaras publicou até Introduction à une phénoménologie de la vie, livro de 2008.

5. Sobre o assunto, são, por exemplo, decisivas as análises de Merleau-Ponty presentes no capítulo sobre o corpo como a expressão e a fala, da Phénoménologie de la perception, e o capítulo sobre o diálogo, da Prose du monde. Nos dois casos, o filósofo mostra que a conquista do sentido se dá sob o registro da intersubjetividade, de modo que não haveria mundo humano fora de um sistema de relações. Esse problema é crucial para quem busca esclarecer a diferença entre a vida biológica e a vida humana. Ora, a discussão com Barbaras mostra que esse problema está intimamente ligado ao modo como se compreende a intersubjetividade, já que dela depende a profundidade ou a densidade da experiência. Quer dizer, é preciso abandonar as concepções tradicionais do vivente (tais como as analisadas criticamente por Barbaras) para que se produza uma fenomenologia da vida (sem o quê não se poderia escapar da filosofia da consciência e dos problemas que disso derivam), mas isso não nos dispensa do desafio de pensar como se produz a singularidade da existência humana no interior da vida comum. É por isso que não basta discutir a relação sujeito/mundo, é preciso dar o passo em direção ao outro, e mostrar que aí se realiza o corte entre vida biológica e vida humana, sem que isso signifique um abandono do primado da vida 
em proveito da consciência. Sendo assim, é possível defender que a compreensão da intersubjetividade em Merleau-Ponty - permeada pelo necessário trabalho crítico desempenhado por Barbaras - pode fornecer elementos para uma fenomenologia da vida, segundo caminhos ainda não explorados por Barbaras. A respeito ver S.S. Ramos. A prosa de Dora. Uma leitura da articulação entre natureza e cultura na filosofia de Merleau-Ponty. São Paulo: Edusp, no prelo.

6. A obra de Barbaras certamente tirará consequências dessa formulação, abrindo novos caminhos para se pensar a temporalidade. Contudo, o que me interessa aqui é iluminar as possibilidades abertas pelo pensamento de Merleau-Ponty ao confrontá-lo com as críticas de Barbaras. Sendo assim, devo salientar que Barbaras não desenvolveu ainda uma perspectiva para que se possa pensar como se dá o acúmulo de experiência. O passado em Barbaras é a nostalgia de uma completude perdida (e irrecuperável no nível da experiência vivente); ele não é algo que se desenha ou que se produz no interior da própria experiência. Voltaremos a esse problema adiante.

7. Dizer que o hábito é uma queda no empírico daquilo que um dia foi criação significa, no caso de Merleau-Ponty, afirmar que os comportamentos adquiridos se realizam tal como a experiência vital: eles permitem a adaptação ao meio - são normativos, portanto -, mas não são produtores de símbolos. A passagem do primeiro ao último Merleau-Ponty realiza essa virada: o filósofo deixa de compreender o acúmulo de experiência - isto é, o passado - segundo a queda no empírico, para compreendê-lo como produção simbólica. Defendo em minha pesquisa que essa passagem depende de uma nova teoria do imaginário, esboçada na obra final de Merleau-Ponty.

8. O que Merleau-Ponty chama de "sistema de equivalências", o qual define o próprio tempo (cf. M. Merleau-Ponty 12, p. 235).

\section{RENAUD BARBARAS E A VITALIDADE DA FENOMENOLOGIA ${ }^{1}$}

Mariana Larison*

Resumo: A fenomenologia de Renaud Barbaras é uma das poucas que continua hoje tentando aprofundar, de maneira original, o caminho aberto pela fenomenologia husserliana. Mas qual é, precisamente, o caminho escolhido por Barbaras para se inscrever na tradição fenomenológica? De que modo se insere no diálogo aberto por esta tradição? Neste texto, tentaremos repor os problemas e conceitos principais que nos permitem compreender a continuidade e a ruptura que apresenta a fenomenologia barbarasiana em relação a esta tradição, assim como alguns dos limites de sua própria proposta.

Palavras-chave: intencionalidade, fenomenologia, Barbaras, vida, desejo.

A obra do filósofo Renaud Barbaras parece se inscrever dentro da longa linha de pensadores que formaram, a partir do começo do século XX, a escola fenomenológica. Seu trabalho, tanto crítico quanto propriamente filosófico, aparece como um esforço por continuar e estender, um século mais tarde, os limites da pesquisa do campo fenomenal a partir de perguntas e motivos contemporâneos. ${ }^{2}$

Mas, se é claro que o projeto barbarasiano se inscreve no vasto campo da escola fenomenológica, não étão óbvio de que modo se produzesta inscrição: em que sentido Barbaras é, efetivamente, um fenomenólogo? O que caracteriza seu pensamento como fenomenológico? Sua referência aos autores da tradição fenomenológica? Utilizar seu vocabulário? Participar

* Pós-doutoranda do Departamento de Filosofia da USP (bolsista Fapesp). 